\title{
$\mathrm{PH} 1044_{\text {debate }}$
}

a debate Patrimonio cultural y cambio climático

| coordina Alejandro García Hermida

\section{¿Cómo se puede reducir el impacto del cambio climático en la preservación de edificios patrimoniales?}

Carmen M. a Muñoz González, Jonathan Ruiz Jaramillo | Dpto. de Construcciones Arquitectónicas, Escuela de Arquitectura, Universidad de Málaga

URL de la contribución <www.iaph.es/revistaph/index.php/revistaph/article/view/4989>

Los edificios históricos se diseñaron y construyeron originalmente considerando las condiciones ambientales propias del lugar donde se construían. Esas características climáticas y su respuesta arquitectónica determinan, para un emplazamiento y momento dados, las condiciones interiores inherentes al edificio (Camuffo 1998).

En la actualidad, la preservación de esta arquitectura histórica y, sobre todo, de su contenido artístico, presenta muchas incertidumbres, debido al calentamiento global del planeta. Está confirmado que en los últimos 50 años se ha producido una elevación de la temperatura bastante significativa en todo el mundo por causas principalmente antropogénicas. Este cambio climático genera sucesos meteorológicos extremos que ponen en riesgo la estabilidad higrotérmica de estos espacios (Prieto et ál. 2020).

Los edificios históricos suelen mostrar una amplia oscilación de las medidas de humedad y temperatura, que pueden generar daños en los materiales que constituyen este patrimonio cultural. ¿Cómo actúa la envolvente de los edificios frente a la evolución de estos parámetros generada con el cambio climático? ¿Cómo reaccionan ante estos cambios las obras de arte que contienen? Estas preguntas demuestran que identificar las variaciones de los parámetros ambientales, así como sus complejas interacciones, es esencial para una evaluación global de riesgos y daños tanto de bienes muebles como inmuebles. Por ello, considerar el comportamiento de las obras de arte expuestas a los cambios de diferentes variables climáticas es un aspecto importante a tener en cuenta en el análisis del rendimiento general del edificio, especialmente cuando esta emplea sistemas activos para generar microclimas estables.
Este patrimonio cultural se ha conservado adecuadamente hasta nuestros días aunque, en la última década, ha surgido gran diversidad de investigaciones centradas en analizar su microclima interior (Herráez et ál. 2014). Estos estudios se basan en una monitorización continua de las condiciones ambientales para evaluar el estado de conservación presente y prever la implantación de sistemas de climatización que garanticen la preservación y el confort térmico.

De esta forma, las nuevas líneas de investigación deben dirigirse a anticipar los efectos del cambio climático. Para ello se están generando herramientas de simulación capaces de analizar las condiciones ambientales en un escenario futuro, facilitando una evaluación a largo plazo que permitirá intervenciones de restauración, rehabilitación o conservación del patrimonio más exactas y fiables al anticipar sus consecuencias de manera integral sobre espacios, ocupantes y bienes muebles (Valseca 2020).

Esta información es valiosa además para los gestores y administradores, que pueden diseñar estrategias para un mejor uso del edificio y sus instalaciones, reduciendo el consumo energético y, como consecuencia, las emisiones de carbono.

Estas nuevas tecnologías permiten realizar simulaciones de las condiciones ambientales del edificio tanto en la situación actual como en escenarios climáticos futuros como, por ejemplo, 2050 o 2100. Es posible realizar simulaciones climáticas en diferentes partes del mundo, estimando las posibles alteraciones de la estructura ambiental y estabilidad higrotérmica de los edificios históricos y de sus obras de arte (Muñoz González et ál. 2020). 


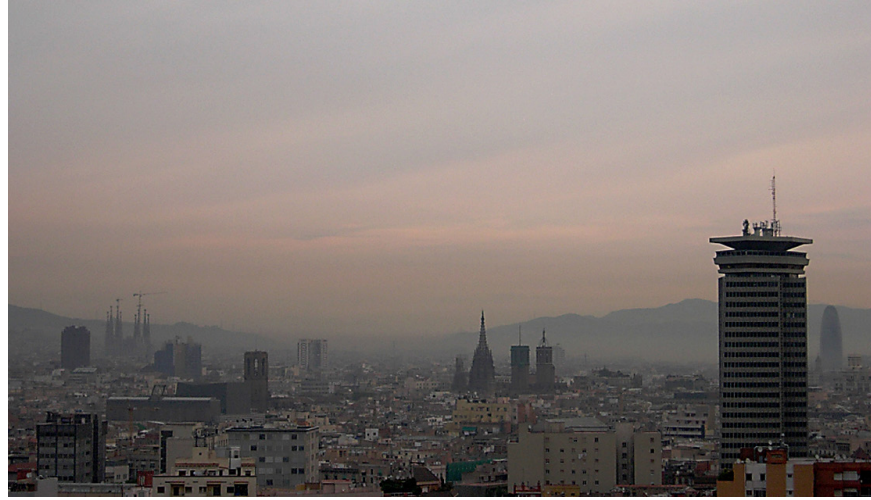

Smog sobre Barcelona | foto Alex R.F.

Los modelos climáticos globales plantean varios escenarios de futuro, pudiendo trabajar con una gran diversidad de variables climáticas que puede incluir lluvias, temperatura, presión, velocidad y dirección del viento o condiciones de cielo nublado. Los citados modelos, combinados con un software de simulación energética de edificios adaptado a espacios históricos, permiten la estimación de los cambios ambientales futuros y su potencial de daño en las obras de arte y en el propio edificio.

Las herramientas de simulación pueden representar el ambiente interior y los mecanismos de transporte higrotérmico en materiales de construcción históricos, teniendo en cuenta también el tipo de uso y los componentes de climatización HVAC (calefacción, ventilación y aire acondicionado). Este enfoque nunca se había realizado antes, ya que los modelos computacionales se utilizan para simular edificios contemporáneos. Hasta la fecha, la aplicabilidad de estos modelos de construcción a edificios históricos estaba siendo limitada, debido a que son construcciones que presentan propiedades y materiales a veces desconocidos.

Frente a la pregunta ¿cómo se puede reducir el impacto del cambio climático en la preservación de edificios patrimoniales?, respondemos que con innovación tecnológica y digital, capaz de anticipar la respuesta y proponer soluciones acordes que mitiguen el cambio climático y sus dramáticas consecuencias.

\section{BIBLIOGRAFÍA}

- Camuffo, D. (1998) Microclimate for cultural heritage. Amsterdam: Elsevier Science

- Herráez, J., Enríquez de Salamanca, G., Pastor, M.J. y Gil, T. (2014) Manual de seguimiento y análisis de condiciones ambientales. Madrid: Ministerio de Educación, Cultura y Deporte

- Muñoz González, C.M., León Rodríguez, A., Suárez Medina, R. y Ruiz Jaramillo, J. (2020) Effects of future climate change on the preservation of artworks, thermal comfort and energy consumption in historic buildings. Applied Energy, vol. 276, 2020, 115483

- Prieto, A., Verichev, J., Silva, A. y de Brito, J. (2020) On the impacts of climate change on the functional deterioration of heritage buildings in South Chile. Building and Environment, 1-15

- Valseca, R. (2020) Los edificios históricosse adaptanal cambio climático. IDESQBRE, ciencia para ti. Fundación descubre, 14 de diciembre de 2020. Disponible en: https://idescubre. fundaciondescubre.es/noticias/los-edificios-historicos-seadaptan-al-cambio-climatico/ [Consulta: 20/07/2021] 